\title{
Inheritance and Innovative Development of Jin Opera Culture in Colleges and Universities in Shanxi
}

\author{
Li Yanfeng \\ School of Music, Shanxi University, Taiyuan, Shanxi, China \\ Keywords: Shanxi opera, culture, Shanxi University, inheritance and innovation \\ Abstract: Jin opera culture is one of the treasures of Chinese traditional excellent culture. \\ College students are the key to the future development of the country and its strength \\ .They have the mission significance for carrying forward and inheriting traditional culture. \\ This paper investigates the cultural development of Jin opera in Shanxi Province. This \\ paper analyzes the inheritance status and difficulties of Shanxi opera culture, and puts \\ forward the inheritance and innovation issues of Jin opera culture in the setting of Shanxi \\ Colleges and universities, and feasible countermeasures for further development.
}

\section{Introduction}

The Chinese nation has a long history and splendid civilization. It has nurtured an excellent traditional culture with a long history, deep roots, and rich diversity. With the continuous development of my country's economy, the improvement of comprehensive national strength, and the improvement of people's living standards, ordinary people are paying more and more attention to the excellent traditional Chinese culture and building cultural self-confidence. At the same time, China's incredible traditional culture has also gone abroad and into the world and has been favored by the people of other countries.

Whether it is the attention of the domestic people or the love of foreigners, it is the spread and development of China's excellent traditional culture. Shanxi is the cradle of Chinese opera, and Jin opera is typical of Shanxi opera. In recent years, it has reappeared with the support of policies such as intangible cultural heritage protection, public cultural service construction, cultural industry development, and funding from the National Art Fund. However, there are still problems in the inheritance and development of Jin Opera, such as the shortage of educational resources, the shortage of high-end performing talents, the lack of successors in the music creation team, and the decline of audience and fans year by year. In 2017, the four departments of the Central Propaganda Department, the Ministry of Education, the Ministry of Finance, and the Ministry of Culture issued the "Opinions on the Implementation of Chinese Opera on Campus." Opinions pointed out that by 2020, Xiqu will be normalized, institutionalized, popularized, and fully covered in campuses. Based on this background, this research has researched the inheritance and development of Jin Opera culture among college students in Shanxi. 
2. Investigation on the current situation of Jin opera culture's inheritance in Shanxi colleges and universities

To fully understand the inheritance of Jin opera culture in Shanxi colleges and universities, the author took Shanxi college students as the survey subjects, used the questionnaire star software to design questionnaires, and distributed the questionnaires through social software such as WeChat. As of November 25, 2021, the background received a total of 4144 valid questionnaires were received. This questionnaire survey covers a wide range of universities in Shanxi, which fully reflects the spread of Jin opera culture, including 863 from Shanxi University in Taiyuan, 222 from North University of China, ten from Taiyuan Normal University, and Shanxi Institute of Applied Science and Technology 195 copies; there are 1080 copies from Changzhi College, 293 copies from Yuncheng College, 478 copies from Datong University, 959 copies from Jinzhong College, and 44 copies from Xinzhou Normal University in other cities in Shanxi Province.

\subsection{College students in Shanxi have a positive attitude towards Jin opera cullture}

From the statistical results of several questions in the questionnaire survey: First, $87 \%$ of college students in Shanxi universities are not fans of Jin opera, but $59 \%$ of college students' relatives and elders like Jin opera. Second, 53.22\% of universities believe that they don't know much about Jin Opera, but more and more young people are beginning to pay attention to the culture of Jin Opera; $11.67 \%$ of college students believe that Jin Opera occupies an important position in the hearts of young people; $16.07 \%$ of college students think that Jin Opera is facing severe problems The situation and inheritance are difficult. $13.21 \%$ of college students think that young people do not accept Jin opera. Third, $78 \%$ of the students in the survey believe that the culture of Jin opera is significant to the development of Shanxi culture. At this stage, most of the channels for college students in Shanxi to understand Jin opera are through TV and Internet media, parks, temple fairs, other venues, and elective courses offered by universities. Still, 16\% of college students don't understand and have never heard of Jin opera.

It can be seen that the audience of Jin opera is still too old. College students are obsessed with Jin opera in the minority. The enthusiasm of their elders who like Jin opera will also indirectly affect college students' cognition of Jin opera. Nevertheless, more and more college students accept the culture of Jin opera, and the promotion of the culture of Jin opera has penetrated the hearts of students. They hold a positive attitude towards the spread of Jin opera culture.

\subsection{The culture of Jin opera is relatively strong in Shanxi's colleges and universities, but the intensity and depth of the dissemination are insufficient}

The survey on the specific measures for the spread of Jin opera culture in Shanxi colleges and universities shows that $38 \%$ of schools have courses on Jin opera culture, and $32.61 \%$ of colleges have courses on opera culture. Not limited to Jin opera, there are still $29.35 \%$. There are no Chinese opera or Jin opera culture courses in colleges and universities. Among the after-school activities of college students, 59.53\% of colleges and universities have club activities with Jin opera or cultural elements of Jin opera. Through the four departments, including the Propaganda Department of the Central Committee of the Communist Party of China, issued the "Opinions on the Implementation of Opera on Campus" document, by 2020, the campus will achieve total coverage. Shanxi colleges and universities will also carry out specific measures to spread Jin Opera culture to varying degrees. Therefore, the communication atmosphere of Jin opera culture in Shanxi colleges and universities has gradually become strong, and most schools have set up some opera courses and club activities.

However, the questionnaire also surveys the familiarity of some of the classic repertoires of Jin 
opera and famous performing artists. The results of the survey are shown in Figures 1 and 2 below. It can be seen from this that college students don't know much about the specific content of Jin operas, and most of them have not heard of these dramas and performing artists, and the penetration rate needs to be increased. Although college students agreed that Jin opera culture is significant to the development of Shanxi culture, the intensity and depth of the cultural transmission of Jin opera are insufficient.

The last question of the questionnaire survey is to provide some constructive opinions on the dissemination and development of Jin opera culture in Shanxi universities. It can be concluded from the feedback of college students that most students believe that the promotion of Jin opera culture needs to be greatly enhanced. It should not be limited to courses and club culture. There should be more forms that young people like to see and see. The methods of publicity should be diversified, blend into the atmosphere of the times, and be close to the life of college students.

\begin{tabular}{r|c|c|}
\hline 《渭水河》 & 1021 & $24.52 \%$ \\
\hline 《打金枝》 & 1795 & $43.11 \%$ \\
\hline 《金水桥》 & 737 & $17.7 \%$ \\
\hline 《空城计》 & 2471 & $59.34 \%$ \\
\hline 《富贵图》 & 584 & $14.02 \%$ \\
\hline 其他剧目 [送细] & 671 & $16.11 \%$ \\
\hline
\end{tabular}

Figure 1 Which of the following repertoires have you watched? Or which other Jin dramas have you seen?

\begin{tabular}{|c|c|c|c|}
\hline 丁果仙 & 1147 & $\infty$ & $27.55 \%$ \\
\hline 郭兰英 & 2247 & $\longrightarrow$ & $53.96 \%$ \\
\hline 王要夏 & 1251 & $\infty$ & $30.04 \%$ \\
\hline 栗桂莲 & 791 & $\infty$ & $19 \%$ \\
\hline 谢涛 & 688 & 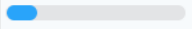 & $16.52 \%$ \\
\hline 苗洁 & 617 & 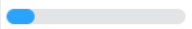 & $14.82 \%$ \\
\hline 武忠 & 595 & 0 & $14.29 \%$ \\
\hline 其他 [详细] & 668 & 0 & $16.04 \%$ \\
\hline
\end{tabular}

Figure 2 Which of the following marginal artists of Jin opera do you know? Or do you know any other Jin opera performers?

\section{The Dilemma of Jin Opera Culture's Inheritance in Shanxi Colleges and Universities}

\subsection{The trend of the times and the diversity of culture have led to more entertainment choices for college students.}

Based on the implementation of various policies for the introduction of Chinese opera culture into campuses, college students' campus culture has increasingly enriched opera-related culture, and students' cognition of traditional culture and humanistic qualities have also improved a lot. However, with the trend of the times and the rapid development of new media and Internet+, students' entertainment options tend to be diversified, and eye-catching film and television dramas and variety shows emerge in endlessly, and the short video live broadcast culture from the media is also rapidly occupying the high ground. College students are too busy to welcome new things, and the number of students who calm down to appreciate the culture of Jin opera is declining. This is also a greater challenge for the spread of Jin opera culture. Only by continuously inheriting and developing Jin Opera culture, keeping pace with the times, and getting close to the interests of young people, can it give full play to the quality of its culture. 
3.2 The narrow spread of Jin opera culture makes college students tired of accepting the culture.

Although both college management and students recognize the positive value of the integration of Jin Opera culture and campus culture, it is not open enough for its dissemination latitude, and there is no penetration and integration. Shanxi colleges and universities are at a disadvantage in terms of the dissemination of Jin opera culture, from the construction of hardware to the teaching staff of software. For example, although many colleges and universities have launched relevant elective courses, they are only theoretical introductions, and have not organized professional teachers, scientific research teams, and publicity teams to study how to deepen the culture of Jin opera into college students' daily after-school learning and entertainment. Another example is the lack of freshness in the introduction of theories. Colleges and universities seldom cooperate with the Jin Theater Troupe or Jin Opera Performing Artists to deepen the impression of students with intuitive visual performances. This is not a problem that can be solved by introducing a few Jin Opera performances and the spark that needs long-term cooperation and exchanges. Therefore, the spread of Jin opera culture is not open enough, which directly causes college students to sit and listen in order to complete the tasks of their superiors.

\section{Exploit the regional advantages of Jin opera and form the regional cultural symbols of Shanxi colleges and universities}

From the perspective of cultural geography, regional culture is a spatial classification of culture, and it is the cohesion and fixation of culture in a spatial region with a specific group of people as the carrier. Local operas such as Peking Opera, Henan Opera, Sichuan Opera, and Jin Opera all reflect the diversity of survival wisdom possessed by regions in a geographical sense. Jin Opera is an important part of Shanxi's regional culture, but in terms of current inheritance and development, it is still limited to some traditional venues such as theaters and temple fairs. From the perspective of the art education of Jin opera, the teaching method of the "mentor-apprentice system" is dominant, and the actual teaching situation is confined to the narrow and closed opera circle. Therefore, even local people cannot fully understand and personally experience Jin opera. In order to avoid the dissemination of Jin opera culture, it is necessary to tap the regional advantages of Jin opera at the level of Shanxi colleges and universities to form regional cultural symbols For example, colleges and universities rely on the Jin Opera general and professional course database to actively create Jin Opera appreciation network video quality courses, establish an open opera culture video course platform, and provide free teaching resources for Jin Opera practitioners, amateurs, and students of primary, middle and high schools.

For another example, colleges and universities cooperate with Shanxi Provincial Jin Theater to organize and record a batch of Jin Opera classics, build a Jin Opera art research database, supplemented by documents, pictures and other materials, and provide rich digital resources for teaching and research workers and opera lovers across the country. In cooperation with the Shanxi Provincial Department of Culture and Shanxi Provincial Television Station, the use of famous teacher workshops and student associations to actively organize Jin Opera performances and singing-related events, while recording and inheriting the art of Jin Opera, pays attention to the spread of Jin Opera culture, and strives to make the traditional culture of Jin Opera deeply rooted in the hearts of the people. Integrating into the lives of the younger generation, while inheriting traditional culture, it can also develop traditional culture, giving it new ideas, new aesthetics, and new artistic conceptions. 


\subsection{Establish a cultural characteristic course of Jin Opera in Shanxi colleges and universities}

In terms of public art courses in Shanxi colleges and universities, through case analysis, a series of provincial-level boutique public art courses of Jin Opera Appreciation were created online and offline, and the Chinese traditional culture and art curriculum system was improved. Relying on the projects funded by the National Art Fund of Shanxi Province Jin Theater, "Dajinzhi", "Qingfeng Pavilion", "Barth Yushi", "Huatianwaizhuan", "Rishengchang Ticket Number", "Red Sorghum" and "Xiongguan Lady", hire the above-mentioned works Core actors go to colleges and universities to carry out theatrical performances and special lectures.

Colleges and universities hire national non-genetic inheritors of Shanxi Provincial Jin Theater such as Wang Aiai, Miao Jie, Tian Guilan, Ma Yulou, Ji Ping, etc. Provincial inheritors: Wang Baochai, Liu Hanyin, Liu Baojun, Ji Rongsheng, Sun Chang, Li Guilian, Song Zhuanzhuan, Wang Xiaoping, Lu Bianchang, etc., Jin Opera Choreographer Liu Heren and Liu Heyao, co-sponsored professional practice courses such as "Jin Opera Songs and Folk Music Performance", "Jin Opera Body Charm and Folk Dance Choreographer", "Jin Opera Wenwu Field Instrumental Music Performance", and "Jin Opera Music Creation". Professional theoretical courses such as "Research on Jin Opera History", "Research on Jin Opera Script Creation", "Ding Pai Vocal Study", and "Study on Jin Opera Xiaodan, Tsing Yi, Xusheng, Hualian Vocal and Body Charm" are offered. Aiming at the actual training of various professional talents in the whole school, the cultivation of humanities and artistic qualities will promote the improvement of professional qualities, and the improvement of professional qualities will verify the adaptability of humanities and artistic qualities, thus laying a solid foundation for the inheritance of Jin opera culture.

\subsection{University teachers strengthen scientific research on Jin opera}

Culture establish Jin Opera cultural communication research teams in Shanxi universities to comprehensively study the performance theory and cultural inheritance and communication theory of Jin Opera art. Relying on the audio-visual materials and oral history of "Wang Aiai Concert", "Dashenjiao Temple", "Shi Jiahua Album II", "Shi Jiahua Album III", "Yang Zhongyi Album", "Zhang Caiping Album" and "Xie Tao Album" recorded by Jin Opera and Symphony Orchestra, Carry out special research on the singing, body rhyme and instrumental accompaniment of Jin opera, explore the performance characteristics of Jin opera, especially carry out the research on the singing of Jin opera of Ding school. Relying on the symphonic works such as "Jin Shan Jigme Yi Jin Opera Large-scale Symphony Concert", "Jin Opera Yin", "Jin Opera Qupai Concert", and "20 Essences of Jin Opera Version", in-depth study of the symphonic composition and arrangement of Jin Opera, and in academic. The journal publishes research papers. In addition, the acoustic research on the sound field of Jin Opera performance can be strengthened. Focus on the visual and auditory effects of performance, and pay attention to the basic and key issues of the inheritance of skills and even the inheritance of performance culture and opera culture. At the same time, focus on the construction of recording studios and strive to record a batch of high-standard recording materials that can be used for acoustic research.

\subsection{Integrate campus culture with cultural elements of Jin opera to create a good communication atmosphere}

Based on the construction of community culture, colleges and universities rely on art-related professional schools and departments to create student clubs such as Jin Opera Art Transmission Institute, Jin Opera Culture School, Jin Opera Performance Sound Field Research Society, supporting teachers for special management, and invite Shanxi Art Vocational College Jin Opera 
professional actors or students on a regular basis Guide club activities. At the same time, formulate the association activities charter, formulate relevant assessment, reward and punishment system evaluation, and promote the work of associations. Carry out the annual Jin Opera Cultural Festival, use the campus stage, radio, self-media network and other channels to showcase the Jin Opera cultural achievements of student associations, and add Jin Opera costume cosplay to the campus animation exhibition, so that students can better participate in the clubs and build a university An exquisite society for the inheritance of Jin Opera art.

Implementation of the "Jin Opera Culture" radiation leadership and innovation and entrepreneurship project of student associations indicates that the team of "Jin Opera Art and Culture Dissemination Volunteers" was formed throughout the school, and in a project-based way, it went deep into colleges and universities in the province, Taiyuan primary and middle schools, communities and towns to carry out Jin Opera cultural dissemination activities, so that students could become Shanxi Jin Opera cultural protection, The main force and new force of inheritance and dissemination. Combining with the actual characteristics of current student associations highlighting innovation and entrepreneurship, encouraging student associations to actively use Shanxi's outstanding traditional cultural and artistic

\section{References}

[1] Li Ping. 2016. The possibility and direction of the revival of traditional opera culture in contemporary campus art education_-Taking the practice path of Sichuan opera as an example [J]. Sichuan Opera, (4): 156-159.

[2] Yan Bing. 2021. The dissemination path and acceptance status of traditional opera culture in colleges and universities [J]. News Research Guide, 21 (06): 66-67.

[3] Liu Youhong, Li Jingguo. 2021. Thoughts on the strategy of integrating Chinese outstanding opera culture into the patriotic education of college students in the new era [J]. Sichuan Drama (01): 156-158.

[4] Ke Zhuoying. 2017. Thoughts based on the investigation of college students' opera cultural literacy-Taking the art of Qinqiang as an example [J]. Drama Literature (02): 127-131. 